\title{
A pandemia na vida das mulheres: Uma reflexão feminista a partir de Moçambique e Brasil ${ }^{1}$
}

\author{
The pandemic in the women's lives \\ A feminist reflection from Mozambique and Brazil
}

Teresa CUNHA ${ }^{2}$

Luísa de Pinho VALLE ${ }^{3}$

\begin{abstract}
Resumo
A pandemia pelo novo Coronavírus, a rapidez da sua disseminaçáo e a terrível visibilidade dos seus impactos são razóes suficientes para propormos uma reflexão feminista que vá para além das visôes sanitária e da política econômica neoliberal dominantes. Nesta perspectiva, apresentamos uma leitura sobre esta realidade a partir da experiência de vida de mulheres em Moçambique e Brasil. Partimos da compreensão que o capitalismo é antissocial, antidemocrático, misógino, colonial e ecocida para colocar em evidência que nada pode ficar como dantes para que a vida, em todas as suas formas, se mantenha e floresça para todas e todos.
\end{abstract}

Palavras-chave: Pandemia. Mulheres. Moçambique. Brasil.

\begin{abstract}
The new Coronavirus pandemic, the speed of its dissemination and the terrible visibility of its impacts are sufficient reasons to propose a feminist reflection that goes beyond the dominant neoliberal sanitarian and political economy views. Thus, we aim a reading about this reality from the life experience of women in Mozambique and Brazil. We argue that capitalism is antisocial, antidemocratic, colonial, misogynistic and ecocidal to put in evidence that nothing can remain as before so that life, in all its forms, is maintained and flourishes for all of us.
\end{abstract}

Key-words: Pandemics. Women. Mozambique. Brazil

1 Este artigo foi escrito com o apoio da Fundação para a Ciência e a Tecnologia de Portugal.

2 Doutorada em Sociologia pela Universidade de Coimbra e pesquisadora sénior do Centro de Estudos Sociais da Universidade de Coimbra e pesquisadora associada do Centro de Estudos Africanos da Universidade Eduardo Mondlane. https://orcid.org/0000-0002-8622-9097; https://www.ces.uc.pt/pt/ ces/pessoas/investigadoras-es/teresa-cunha. Email: teresacunha@ces.uc.pt

3 Doutoranda no programa Democracia no Século XXI, do Centro de Estudos Sociais, Universidade de Coimbra. https://orcid.org/0000-0002-0570-2920. E-mail: luisadepinhovalle@gmail.com; luisavalle@ces.uc.pt 


\section{A pandemia pelo novo Coronavírus e os negócios dos $1 \%$ versus a vida dos $99 \%$}

Estamos a viver uma pandemia por infecção do novo Coronavírus que resulta numa doença a que se convencionou chamar de COVID-19. Esta pandemia apresenta três características muito significativas: (1) uma taxa de transmissáo muito elevada fazendo com que o número de pessoas infectadas aumente exponencialmente a cada dia que passa; (2) é transversal a todos os países e regióes do globo; e (3) tem uma taxa de mortalidade muito elevada dadas as complicaçóes de saúde que gera, nomeadamente, nos sistemas pulmonar e respiratório e a falência multiorgânica subsequente.

Em 26 de janeiro de 2021, o painel da evolução da COVID-19 no mundo, elaborado pelo Centro de Ciência e Engenharia de Sistemas da Universidade Johns Hopkins (EUA), demonstra que foram confirmadas 99.808 .397 pessoas infectadas em todo o globo. Dessas, pelo menos 2.142.826, já morreram. Apesar destes números serem trágicos, o desastre humanitário que está por vir pode ser ainda muito mais grave.

Várias organizaçóes e especialistas epidemiologistas alertam que estes números estão seguramente muito abaixo da realidade e que todos os dias eles sofrem aumentos exponenciais. As razões apresentadas são várias: a) impossibilidade de testar toda a população, pela ausência de testes disponíveis. Ou seja, os números apurados dia-a-dia náo traduzem com exatidão a realidade da extensão da infecção e das mortes uma vez que há muitas pessoas infectadas que permanecem assintomáticas; b) a incapacidade dos serviços de saúde chegarem a todas as populaçóes de forma sistemática nos vários países do mundo; c) há uma subnotificação dos casos de morte por Coronavírus por não ser possível determinar, com rigor, as causas de muitos dos falecimentos; d) os sistemas de saúde estão a colapsar, mesmo em países ${ }^{4}$ em que estes pareciam ser funcionais, devido à pressão causada pelo rápido crescimento de casos de infecção. Além das ausências dos meios de proteção para profissionais de saúde e das incertezas quanto à total eficácia da vacinação; e) há vários países no mundo que não estão a divulgar os dados relativos à sua situação em relação a esta pandemia por motivos vários (guerra, regime político, incapacidade operacional, entre outros). Por outro lado, as consequências sociais, econômicas e políticas, e as potenciais sequelas na saúde das pessoas que recuperaram da doença, estão longe de serem compreendidas e avaliadas.

Vejam-se, a título de exemplo: a Itália, a Espanha, o Reino Unido, Portugal e a França. 
Perante a escala deste fenômeno e dos seus impactos a humanidade está a viver esta experiência com medo, incerteza e perplexidade. Parece-nos que todas as explicaçôes para o que nos está a acontecer são poucas e incapazes de nos fazerem compreender como chegamos até aqui. Além disso, parece ser cada vez mais difícil distinguirmos, com clareza, como nos podemos manter saudáveis física e mentalmente; quais os sinais que devemos seguir para orientarmos o nosso presente e futuro e o das nossas famílias e comunidades; e parece que já não sabemos que mundo afinal é o nosso e como serão os meses e os anos que temos por diante.

O que já sabemos é que ao longo dos últimos 50 anos, apareceram 300 novas patogenias. Está amplamente documentado que $70 \%$ das patogenias que afetam o ser humano hoje, entre os quais o HIV, o ebola, a gripe, a síndrome respiratória do Oriente Médio (MERS, na sigla em inglês) e a síndrome respiratória aguda grave (SARS, na sigla em inglês), surgem quando os ecossistemas florestais são invadidos e os vírus se transferem de animais para pessoas. Da mesma forma, isso ocorre quando se amontoam animais em megaprojetos de produçáo industrial para maximizar os lucros, como é o caso da gripe suína e a das aves. As pandemias, e as crises econômicas e humanitárias que se lhes seguem, deixaram de ser agudas para passarem a serem crônicas. Parece que estamos numa guerra que não cessa de gerar mortes, doenças, pessoas deslocadas e destruição em massa. A ecofeminista indiana Vandana Shiva (2020a), afirma que esta pandemia não é um desastre natural tal como não são 'naturais' os fenômenos climáticos extremos que temos vivido ou testemunhado. As epidemias emergentes, assim como as mudanças climáticas, são intrinsecamente antropogênicas, ou seja, causadas pelas atividades humanas. A chamada 'nova' normalidade do século XXI parece ser a permanência das crises e dos desastres e não a resolução das suas causas profundas.

Porém, é necessário deixar claro que estes fenômenos têm dimensóes e impactos tragicamente desiguais entre regiōes, continentes e populaçóes. É preciso reconhecer que as pandemias, as crises sanitárias e os desastres ambientais são também produtos das desigualdades estruturais no mundo e aprofundam e reforçam essas mesmas desigualdades. Não é verdade que a escala global de uma pandemia como esta tenha feito desaparecer as fronteiras ou que estas não tenham nenhuma importância para o vírus. Pelo contrário, a pandemia pelo novo Coronavírus, como outros desastres e crises, atravessam as fronteiras nacionais sim, mas em grande medida para as reafirmar. Tanto no acesso aos recursos, quanto na capacidade de enfrentar os problemas com dignidade a experiência dos problemas contemporâneos mantêm subjugadas, de forma muito díspar, regiōes, territórios, corpos e os seres que os habitam. A exclusividade dos privilégios que está subjacente a esta lógica de separação entre quem pode ter presente e futuro e 


\section{A pandemia na vida das mulheres

quem pode ser descartado, muitos países e as suas populações são transformados em territórios de sofrimento e sacrifício. São milhóes de seres humanos e nãohumanos que são imolados para que se mantenham as cadeias de acumulação de lucros inimagináveis por parte de elites cada vez mais ricas e mais restritas e que se consideram proprietárias do mundo.

Enquanto a maioria das/os cidadãs/ãos do mundo são chamadas/os a fazer todos os sacrifícios necessários para enfrentar a pandemia, o que pode incluir perder o emprego e os rendimentos, perder a saúde física e mental, não poderem sepultar as suas pessoas amadas falecidas, experimentarem o inferno da violência doméstica e o isolamento, alguns fazem da pandemia mais uma oportunidade de negócios ultramilionários.

Segundo a Bloomberg Billionaires Index ${ }^{5}$, o ano de 2020 foi muito próspero para as 500 pessoas mais ricas do planeta. O relatório final do ano mostra que elas adicionaram US $\$ 1,8$ trilhão às suas riquezas em 2020, acumulando um patrimônio líquido total de US $\$ 7,6$ trilhóes. Os indexadores registraram o maior ganho anual na história da lista de bilionários do mundo, com um aumento de $31 \%$ na riqueza dessas pessoas. Os três primeiros nomes da lista são Jeff Bezos da Amazon, Elon Musk da Tesla e SpaceX, e Bill Gates da Microsoft. Bezos teve um crescimento de 78,9 bilhóes de dólares, (68,7\%), ao longo dos doze meses do ano. Musk acumulou ao seu patrimônio 133 bilhôes de dólares, o que representou um aumento de $482 \%$ na sua fortuna. E Gates que, recentemente ${ }^{6}$, acumula o título de maior latifundiário dos Estados Unidos da América (possui o total de 209 mil hectares de terra agrícola), acrescentou mais 18,4 bilhóes de dólares, (16,3\%), ao seu patrimônio, em 2020.

\section{A pandemia pelo novo Coronavírus e a milenar experiência da discriminação por se ser mulher}

A realidade que a pandemia, inaugurada pelo novo Coronavírus, nos tem imposto tem gerado alteraçóes profundas no quotidiano das pessoas todas e tem levado os governos e os estados nacionais a usarem o estado de emergência como medida de mitigação e controlo da doença. Isso implica, em geral, a implementação das seguintes medidas: (1) confinamento em casa; (2) restriçóes severas à mobilidade; (3) restrições severas à aglomeração de pessoas, o chamado afastamento social, com proibição de espetáculos, cultos, manifestações, marchas,

5 Ver Bloomberg (2020).

6 Ver Glamurama (2021) e Canal Rural (2021), dentre outras publicações. 
festas familiares, ou outros eventos que envolvam grandes conjuntos de sujeitas/os; (4) encerramento das atividades comerciais consideradas não essenciais das quais se excluem provisão de alimentos, água potável, eletricidade, gás, medicamentos e outros serviços de saúde; (5) encerramento de escolas e universidades e transferência das suas atividades para meios digitais ou à distância, conforme as possibilidades técnicas existentes; (6) encerramento de fronteiras e cancelamento de vistos; (7) restriçóes severas à mobilidade aérea e ao uso dos espaços aéreos nacionais; (8) em casos mais graves têm-se adotado medidas de cerco sanitário de territórios/populaçôes; (9) vigilância policial e até militar do cumprimento das medidas e punição das/os transgressoras/es; (10) o uso de vigilância digital e por GPS7 das/os cidadâs/ãos, dos seus movimentos e contatos.

Do mesmo modo, ao nível da economia, trabalhadoras/es, empresárias/os e empresas, estão a ser afetadas pela situação da saúde pública mundial e pelas medidas de contenção, mitigação e prevenção do alastramento da COVID - 19. As sucessivas declaraçóes do estado de emergência, têm vindo a limitar direitos cívicos e políticos, a aumentar a militarização das sociedades, a facilitar a especulação de preços nos mercados de consumo de produtos básicos, a introduzir alteraçóes no padráo do consumo, da mobilidade e de comportamento social e a reorientar a produção industrial. As consequências mais visíveis são o desemprego; a falta de produtos básicos de higiene; o aumento incontrolado dos preços de bens essenciais; a precarização das condiçóes de trabalho e de segurança humana e alimentar; o aumento da xenofobia; aumento da violência contra as mulheres de todas as idades (OCHA-Services, 2020); a supressão ou restrição de direitos civis e políticos como o direito à greve, adiamento de eleiçóes e outros; e, em casos de economias fortemente caracterizadas por atividades de caráter informal, uma drástica perda de meios para obtenção de renda (moeda fiduciária) e, portanto de sobrevivência.

Por que é importante trazer para esta reflexão estes dados? A principal razão é a que se prende com o fato destas condições reforçarem, de modo explícito, as vulnerabilidades a que a maioria das mulheres do mundo, em especial as dos espaços historicamente colonizados, estão sujeitas. Sabemos que os riscos de infecção para as mulheres, além de extremamente elevados, são específicos por causa das desigualdades de poder que atravessam as relaçóes de gênero. Esta situação tem, pois, impactos determinantes nas suas vidas e nas vidas das suas famílias e comunidades que dependem, em grande medida, do seu trabalho tanto aquele que não é pago como aquele que gera renda.

Por outro lado, é absolutamente central reconhecer que a experiência milenar das mulheres nos tem ensinado que não importam as pandemias, as crises ou as

Global Positioning System. 
calamidades, nós, os seres que nos representamos como femininos, somos sempre as mais atingidas, as menos protegidas, as mais discriminadas (FEDERICI, 2004; CUNHA, 2017). É claro, que nem todas as mulheres e as meninas sofrem com a mesma intensidade, nem e/ou enfrentam em igualdade de condiçóes as consequências da pandemia. Porém, somos sempre as menos ouvidas e tidas em pouca, ou nenhuma, consideração os nossos conhecimentos, as nossas sabedorias e as nossas práticas que identificam, compreendem e resolvem problemas. $\mathrm{Na}$ verdade, o que esta pandemia também mostra de forma límpida e cristalina, é a misoginia estrutural do nosso tempo que continua a submeter as mulheres de todas as idades e de todos os cantos do planeta a todos os tipos de vulnerabilidades e violências, especialmente aquelas que habitam os lugares de sacrifício do mundo.

Os dados do relatório Tempo de Cuidar: o trabalho de cuidado náo remunerado e mal pago e a crise global da desigualdade, da OXFAM-Brasil (2020b), revelam que as mulheres estão na linha de frente de uma economia três vezes superior à de todo o setor tecnológico, apesar de não terem o seu trabalho reconhecido, nem serem remuneradas. Por isso elas continuam a serem as pessoas mais empobrecidas no mundo. De todas elas, porém, as africanas são as que mais sofrem com estas desigualdades: apenas 22 homens possuem mais riqueza do que todas as mulheres de África. Isto quer dizer que, mais de 680 milhóes ${ }^{8}$ de mulheres africanas, juntando todas as suas riquezas, não conseguem acumular o mesmo do que aquilo que possuem apenas duas dezenas de homens. $\mathrm{Na}$ América do Sul', das quase 220 milhóes de mulheres do continente, 109 milhóes estão no Brasil ${ }^{10}$. A despeito da pandemia, 33 novos brasileiros estão no ranking dos Bilionários do Mundo 2020, publicado pela revista Forbes ${ }^{11}$. Das onze maiores fortunas brasileiras do ranking mundial, somente uma está hoje, após o falecimento do marido, nas mãos de uma mulher ${ }^{12}$, Dulce Pugliese (da Amil Assistência Médica Internacional e Dasa).

Se tivermos em consideração as desigualdades internas existentes nos dois continentes, além das diferenças histórico-política-econômicas entre África e América do Sul, isto quer dizer que são milhôes de mulheres realmente miseráveis no sentido de não possuírem os recursos materiais e simbólicos para poderem viver a uma vida longa, digna de ser vivida, sem medos e violências, com conforto e verem respeitada a sua inalienável integralidade física e mental.

8 Informações disponíveis em Country Meters (s/d).

9 Idem.

10 Idem.

11 Ver Juliana Andrade (2020).

12 Ver Rebeca Fuks (2021). 
Por isso, parece-nos fundamental afirmar que a primeira coisa a fazer é provocar e alimentar uma reflexão feminista que seja também o reconhecimento da interseccionalidade (MCCLINTOCK, 1995; BRAH, PHOENIX, 2004) das opressóes levadas a cabo pelo capitalismo, o colonialismo e o heteropatriarcado (CUNHA, 2014, 2017). Estes, a nosso ver, são os sistemas mais poderosos de dominação, exploração e aniquilamento que estão presentes no nosso tempo (OYĚWÜMÍ, 1997; MENDOZA, 2010; MIES, 2014; PEREZ OROZCO, 2014; FEDERICI, 2019). Propomos, então, esta reflexão feminista que é também um manifesto pela vida em todas as suas formas. Por outro lado, propomo-nos pensar pelas nossas cabeças e desobedecer sempre que nos digam que o Coronavírus é razão suficiente para cortar as nossas liberdades, os nossos direitos, aumentar o nosso trabalho não-pago, intensificar as violências contra nós, impedir a nossa mobilização social e promover a militarização das nossas vidas.

\section{Olhando para a pandemia a partir de Moçambique e Brasil}

Olhamos para este nosso mundo, povoado pelo novo Coronavírus, a partir de Moçambique e Brasil, os nossos lugares de enunciação. Curiosamente, mas sem espanto, percebemos que apesar das diferenças histórico-socioeconômicas e culturais entre Moçambique e Brasil a experiência e os impactos da pandemia pelo Coronavírus na vida das mulheres têm muitas coisas em comum.

3.1- Moçambique é um país onde a maioria da população são mulheres ${ }^{13}$, sobretudo jovens; a prevalência de casamentos precoces e forçados das meninas é muito elevada ${ }^{14}$; a infecção pelo HIV é superior a $13 \%$ e atinge 3 vezes mais as mulheres do que os homens ${ }^{15}$; a violência praticada contra a mulher atinge níveis alarmantes ${ }^{16}$ - uma em cada 3 refere que já sofreu algum tipo de violência na sua vida; onde apenas $1,4 \%$ tem escolaridade de nível secundário e em meio rural 71,6\% são analfabetas (OSÓRIO; SILVA, 2018: 177); em que cabe essencialmente às mulheres a provisão de alimentos e o cuidado com ascendentes e descendentes vulneráveis e/ou dependentes. O país tem cerca de 29 milhóes

13 Segundo os Censos de 2017, Moçambique conta com 27.909.798 pessoas das quais 14.561.325 (52\%) são mulheres e 13.348 .446 (48\%) são homens.

14 Ver Unicef (s/d).

15 Ver Moçambique (s/d).

16 Segundo o INE-MZ, pelo menos 37,2\% delas denunciavam que já tinham sido vítimas de violência física e sexual na faixa etária entre os 15 e os 49 anos de idade ficando por saber o que acontece em idades inferiores e superiores. Ver Conceição Osório e Tereza Cruz e Silva (2016: 154). 
de habitantes e conta apenas com 0.07 médicas/os para cada 1000 habitantes ${ }^{17} \mathrm{e}$ segundo revela um estudo do Ministério da Saúde existe menos de uma Unidade Sanitária por 10.000 habitantes. O inventário, realizado pelo Instituto Nacional de Saúde, revela também que 19\% das 1.643 unidades sanitárias não tem energia elétrica, $12 \%$ não dispóe de fonte de água dentro ou no recinto da unidade e que $21 \%$ não tem casa de banho para pacientes. Em Moçambique, segundo as Nações Unidas, existem 1,7 milhóes de pessoas que vivem em emergência alimentar. Esse número foi apurado somente para o período entre outubro/2019 e fevereiro/2020.

Em Moçambique, como em muitos outros países, a emigração por motivos econômicos é uma realidade transversal. Dezenas de milhar de emigrantes moçambicanas/os a residir na República da África do Sul, onde a doença tem níveis de contaminação muito elevados. Assim esta realidade constitui um risco especialmente grave para as mulheres e as crianças das famílias que as/os recebem nos períodos de férias ou festividades. A mobilidade humana, mesmo quando é voluntária, não se processa sem riscos para quem parte ou para quem chega. Deixa de ser um direito para se tornar em mais um risco de vida.

As populações atingidas mais duramente pelas cheias e os ciclones Idai e Keneth em 2019, Chalane em 2020 e Eloise em 2021 não têm recursos suficientes para ultrapassar os problemas e perdas que daí advieram, nomeadamente em termos de domicílio, abastecimento de água, alimentação e cuidados de saúde primários. Do mesmo modo, as culturas alimentares perderam-se ou são largamente insuficientes para garantir uma nutriçáo básica a todas e todos. Estes elementos tornam estas pessoas particularmente vulneráveis à infecção pelo novo Coronavírus, em especial as mulheres e as meninas que, em muitas práticas culturais, são as últimas das famílias a serem contempladas com a comida disponível. O que se torna mais dramático é sabermos que em muitos outros lugares do planeta, onde tragédias semelhantes estão a ocorrer, as mulheres partilham estas mesmas angústias e sofrimentos (SHIVA; SHIVA, 2020; PÉREZ OROZCO, 2017; FEDERICI, 2018).

A guerra no centro e a guerra no norte do país estão a provocar a destruição de infraestruturas essenciais (pontes, estradas, postos de saúde, escolas, postos administrativos); a morte de milhares de pessoas e a deslocação forçada de centenas de milhar; o corte no abastecimento de bens essenciais à vida; o aumento drástico da concentração populacional nas sedes provinciais ou de distrito; o medo e o pânico generalizados; e a normalização da violência como método de resolução de conflitos; o aumento da prostituição feminina como moeda de troca para acesso a bens essenciais à sobrevivência. Esta situação faz com que estas populaçóes fiquem

Ver Mundi (s/d). 
especialmente vulneráveis à contração da COVID - 19, em particular as mulheres e as meninas que são as mais vulneráveis a todas estas violências.

Em países como Moçambique os meios de comunicação social de massas têm uma capacidade de difusão da informação relativamente limitada. No campo, onde vive a maioria das pessoas (70\%) é difícil fazer chegar mensagens sobre modos de prevenção da doença, das possibilidades de enfrentamento ou das suas consequências. A pluralidade linguística do país, a sua extensão territorial, a ausência de infraestruturas de comunicação através de rádio, televisão, telefone celular, jornais e a fraca capilaridade dos serviços do Estado em muitas zonas do país, são outros fatores de risco em situação de pandemia e alarme para a saúde pública.

Tal como muitos outros países no continente Africano, Moçambique tem uma economia muito porosa e dependente da ajuda externa (CASTELBRANCO, 2010). Não existe praticamente tecido industrial, sendo o país praticamente dependente do exterior no que respeita a produtos manufaturados. A soberania alimentar está gravemente ameaçada pela importação maciça de produtos agrícolas do estrangeiro e a falta de investimento na agricultura familiar camponesa e nos circuitos comerciais de proximidade. Isso significa uma enorme fragilidade perante alteraçóes drásticas da economia global e regional. Em caso de calamidade o país tem profundas dificuldades em responder adequadamente aos desafios que lhes são postos.

3.2 - O Brasil possui uma extensão territorial de $8.514 .876 \mathrm{~km}^{2}$ e o número populacional gira em 213.889.02418. Em 2019, o IBGE - Instituto Brasileiro de Geografia e Estatística, pela Pesquisa Nacional por Mostra de Domicílio PNAD, demonstrou que $56,10 \%$ da população brasileira é negra ${ }^{19}$. Dados do Ipea - Instituto de Pesquisa Económica Aplicada de 2016, mostram que as mulheres brancas assalariadas no Brasil recebem $70 \%$ a mais que as mulheres negras assalariadas brasileiras ${ }^{20}$. Lélia Gonzales (1984), ao apresentar sua análise sobre as construções de representaçôes das mulheres negras na sociedade brasileira, evidenciou a inseparabilidade do racismo do sexismo na vida da grande maioria da população feminina do país. E ela acrescenta: Para nós o racismo se constitui como a sintomática que caracteriza a neurose cultural brasileira. (GONZALES, 1984: 224) Partimos da compreensão de que as mulheres negras no Brasil estão sujeitas às duas violências indissociadas, historicamente.

18 Ver Country Meters (s/d).

19 Ver Nathália Afonso (2019).

20 Ver USP (2020). 
Infelizmente, o Brasil está dentre os primeiros do mundo ${ }^{21}$ na prática do crime de feminicídio. Segundo a Organização Mundial da Saúde (OMS), o número de assassinatos chega a 4,8 para cada 100 mil mulheres. O Mapa da Violência de 2015 aponta que, entre 1980 e 2013, 106.093 pessoas morreram por sua condição de ser mulher. As mulheres negras são ainda mais violentadas. Apenas entre 2003 e 2013, houve aumento de $54 \%$ no registro de mortes, passando de 1.864 para 2.875 nesse período. Muitas vezes, são os próprios familiares (50,3\%) ou parceiros/ex-parceiros $(33,2 \%)$ os que cometem os assassinatos (AGÊNCIA BRASIL, 2017).

Um monitoramento realizado pela parceria construída entre sete mídias independentes no Brasil apurou que os casos de feminicídio no país, somente nos dois primeiros meses da pandemia, aumentaram em 5\% em relação a igual período de 2019. Entre março e abril de 2020, 195 mulheres foram assassinadas, enquanto em março e abril de 2019 foram 186 mortes. Entre os 20 estados brasileiros que liberaram dados das secretarias de segurança pública, nove registraram juntos um aumento de 54\%, outros nove tiveram queda de 34\%, e dois mantiveram o mesmo indice (COLABORA, 2020). E, ainda, o Anuário Brasileiro de Segurança Pública de $2019^{22}$, demonstrou que $61,62 \%$ das mulheres que sofreram feminicídio no país eram negras (SEGURANÇA PÚBLICA, 2019).

Com a chegada do novo Coronavírus, também, veio à tona uma política de governo genocida no Brasil. Essa afirmaçáo, como destacam Milanez e Vida (2020), não é retórica, mas sim a confirmação de um longo e continuado processo de extermínio das populaçóes indígena e negra brasileiras. Soma-se a essa perversa realidade o enfrentamento da insegurança alimentar. Já no mês de julho de 2020, a OXFAM-Brasil (2020a) declarava: O Brasil está entre os prováveis epicentros da fome no mundo, juntamente com Índia e África do Sul, onde milhóes de pessoas estão à beira da grave insegurança alimentar e pobreza extrema. A política socioeconômica neoextrativista (SVAMPA, 2015, 2019; ACOSTA; BRAND, 2017; GAGO, 2015) no país não é criação do atual governo, remonta às investidas das políticas neoliberais transnacionais sobre a América Latina das últimas cinco décadas. Porém, com a pandemia inaugurada pelo novo Coronavírus, a política do atual governo encontrou uma brecha para avançar nos incentivos ao agronegócio, à grilagem e invasão das terras indígenas e quilombolas, na criminalização e violência autorizada sobre as comunidades negras e indígenas urbanas e rurais, na desconstitucionalização das garantias, deveres e proteçôes dos direitos sociais, dentre tantas outras medidas e atuações pró-morte perpetradas ao longo do ano de 2020 no território brasileiro.

21 Taxa de feminicídios no Brasil é a quinta maior do mundo. (BRASIL, 2017)

22 Segurança Pública (2019). 
3.3 - Tendo em consideração todas estas características e as condições e restrições impostas pelas políticas governamentais de cada um dos dois países, são vários os impactos que estão a atingir as populaçóes, com uma especial incidência na vida e nos corpos das mulheres. Para pensar neles é necessário começar por ter consciência de que as mulheres não param de menstruar, de engravidar e de parir; continuam a enfrentar a escassez de alimentos, de autoridade e poder para resolver os conflitos e viver em paz; elas continuam a fazer face à crescente violência dentro e fora das suas casas. Às mulheres continuam a caberem as tarefas de cuidar das crianças e das pessoas mais idosas; elas são responsáveis por prover medicamentos e comida em seus lares, para toda a família. As mulheres e as meninas continuam a ser as pessoas mais suscetíveis aos abusos sexuais e à má-nutriçẫo porque as crenças e as práticas culturais que as subjugam não se alteraram, antes se reforçaram. As mulheres continuam a atravessar as fronteiras da violência todos os dias.

Como explica Lilia Schwarcz (2020: 174), todas as sociedades constroem os seus próprios marcadores de diferença. Usa-se a diferença física para a formação de estereótipos sociais marcados, predominantemente, pela inferioridade. Logo, a pessoa estereotipada passa a objeto de discriminação e violência. Especificamente sobre os marcadores sociais listados na realidade atual do Brasil, Schwarcz (2020) aponta que:

(...) estão incluídas categorias como raça, geração, local de origem, gênero e sexo, e outros elementos que têm a capacidade de produzir diversas formas de hierarquia e subordinaçâa. Em nossa sociedade, o uso perverso de tais categorias tem gerado todo tipo de manifestaçáo de racismo, levado ao feminicídio, produzido muita misoginia e homofobia, bem como justificado uma disseminada "cultura do estupro", cujos números continuam alarmantes mas são, ao mesmo tempo, majoritariamente silenciados no país (...) (2020: 175).

Sabemos ainda que em contextos de emergência social os impactos com base nas construçóes sociais de gênero são vários e importantes. É necessário, pois, promover a discussão e ouvir atentamente as análises e as ideias das mulheres e meninas acerca do que está a acontecer e do que pode estar para vir. Muitas têmse reunido para pensar, refletir e partilhar conhecimentos, procurar alternativas e contrariar o isolamento a que estão a ser obrigadas. A análise que se segue é o resultado de muitos desses encontros. Ativistas e intelectuais feministas têm intervindo e compartilhado ideias, experiências práticas e propostas de alternativas. A nossa proposta é a sistematização das linhas de força destas reflexôes levadas a cabo em webinárias promovidas por coletivos de mulheres em Moçambique e Brasil entre abril e junho de 2020. 


\section{Treze impactos da COVID-19 na vida das mulheres e meninas nas várias esferas da vida}

A escuta das mulheres e das meninas ao longo dos passados meses permite-nos identificar e explicitar algumas das coisas que estão a acontecer nas nossas vidas e que estão a transformar os nossos quotidianos numa dura luta permanente pela vida, pelo respeito, a dignidade humana e a justiça sexual. Estruturamos esta reflexão partilhada em 4 grandes temas: Violências; Saúde; Trabalho e rendimento; e, Cidadania e poder. Colocamos em evidência o que nos é comum para além das fronteiras nacionais e continentais. Mostramos assim que as lutas feministas são todas necessárias e que a nossa imaginaçáo de um mundo onde caibam muitos mundos é uma tarefa tanto solidária quanto internacionalista. Estes são, pois, os 13 impactos da pandemia na vida das mulheres sentidos a partir de Moçambique e Brasil.

\section{1- Violências}

1/ Violência na família

O aumento da violência em contexto familiar devido ao confinamento obrigatório e no espaço do trabalho, nomeadamente no trabalho sexual e doméstico. Aumento do feminicídio. A convivência forçada e permanente com os agressores dentro das suas casas está a empurrar muitas mulheres e meninas para uma situação de enorme gravidade em temos da sua saúde física e mental, quando a própria vida já não foi extinta;

\section{2/ Violência nos espaços públicos}

$\mathrm{O}$ aumento da violência (roubos, ataques sexuais) relacionada com a mobilidade das mulheres quando se deslocam para irem às suas machambas, roçados, pequenos negócios, compras, órgãos do Estado e governos. Cada vez mais os espaços públicos são lugares de perigos eminentes para a integridade física e sexual das mulheres e os relatos de estupros e outras formas de violência contra elas nas ruas, nas escolas, nas instituiçóes que as deveriam defender, são cada vez mais recorrentes; 
3/ Violência sexual e gravidezes indesejadas ${ }^{23}$

O aumento das violaçóes sexuais perpetradas no âmbito da família devido à desigualdade de poder e as gravidezes indesejadas que daí decorrem, têm trazido para a vida das meninas e das mulheres mais e novos problemas com que têm que lidar e enfrentar.

\section{2- Saúde}

4/ Aumento de doenças sexualmente transmissíveis e infectocontagiosas

A falta de proteção na vida sexual imposta por tabus culturais, falta de informação ou relações de poder altamente desiguais; o aumento da prostituição para obtenção de renda ou recursos; o retorno de familiares emigrados infectados, tem provocado o crescimento de infecçóes por HIV e outras doenças sexualmente transmissíveis e ainda outras infectocontagiosas como a hepatite e a tuberculose;

\section{5/ Aumento de fatores de risco de infecção pelo novo Coronavírus}

A falta de equipamentos de proteçáo no trabalho, especialmente para as profissionais de saúde, da alimentação e trabalhadoras domésticas que são a maioria das mulheres assalariadas; as ausências de acesso à água potável, ao saneamento, a medicamentos e testes de diagnóstico, aumentam exponencialmente os riscos de infecção COVID - 19.

6/ Aumento de doenças mentais

O aumento de doenças do foro mental provocado pelo isolamento, a violência e o medo: depressáo, ansiedade, falta de autoestima, ataques de pânico.

7/ Aumento da má-nutrição e da fome

O aumento da má-nutrição por escassez de alimentos que pelas regras culturais dominantes costumem deixar as mulheres para o fim no acesso aos recursos e à alimentos e que piora de forma trágica em caso de calamidade pública.

Ver Naçôes Unidas, UN (2020). 


\section{8/ O aumento da mortalidade materna e materno-infantil}

O aumento da mortalidade materna e materno-infantil pela crescente falta de acesso a cuidados adequados de saúde em virtude do fecho das unidades sanitárias disponíveis, de serviços hospitalares ou ainda pelo receio das/os profissionais de saúde em prestar auxílio e apoio obstétrico ao nível local e sem condiçóes de autoproteção; e, ainda, a criminalizaçáo do aborto que leva a milhares de mulheres a se submeterem a práticas clandestinas, insalubres e com alto risco para suas vidas.

\section{3 - Trabalho e rendimento}

\section{9/ Aumento do trabalho não-pago}

A divisão sexual do trabalho na esfera doméstica, em muitos casos o teletrabalho e a obrigação de conciliar o trabalho profissional com o cuidado diário e educativo e o apoio emocional com ascendentes e descendentes em modo contínuo; nos meios urbanos, o fecho ou a limitação do acesso a todas as infraestruturas públicas e privadas de apoio (escolas, creches, acesso à internet $\mathrm{e}$ outras); a ausência ou a dificuldade em obter apoio familiar ou de vizinhança para redistribuição das tarefas do cuidado, por causa do confinamento, têm trazido para a vida das mulheres um aumento brutal do seu trabalho não-pago.

\section{0/ A crise dos cuidados e a ética reacionária dos cuidados}

Muitas feministas têm chamado à atenção para a realidade que designam de crise dos cuidados. Elas têm vindo a chamar à atenção que esta pandemia tem tornado visível a ausência de políticas públicas adequadas para que os cuidados necessários à reprodução social se processem de forma eficaz e sustentada. A crise dos cuidados está a colocar em causa a coesão social, a saúde física e mental de muitas/os, e a segurança daquelas/es que, por diversas razóes, são dependentes. A outra face desta crise dos cuidados é o aumento do conservadorismo sexual que advoga uma ética reacionária do cuidado que normaliza as tarefas e responsabilidades do cuidado, nas esferas doméstica e da comunidade, como uma segunda natureza das mulheres pelas quais não devem ser pagas e com as quais se devem contentar porque são a manifestação mais sublime da sua feminilidade ${ }^{24}$.

Ver Amaia Pérez Orozco (2006, 2017). 
11/ Perda de emprego e rendimentos: empobrecimento

A perda do emprego assalariado; a especulação dos preços de bens essenciais; a restrição drástica para o desenvolvimento das atividades econômicas, nomeadamente as que são consideradas informais, mas que são a fonte de renda de uma grande maioria das mulheres e suas famílias; a ausência de políticas públicas efetivas de segurança social e de proteçáo do emprego e dos rendimentos das famílias, está a aumentar drasticamente o já conhecido e comprovado empobrecimento das mulheres.

\section{4 - Cidadania e poder}

12/ O aumento do abuso do poder sobre a vida e os corpos das mulheres

Com, ou sem, estados de emergência declarados o abuso de poder sobre os corpos e a vida das mulheres por parte das forças de segurança (policiais e militares) vem a aumentar, drasticamente, uma vez que alguns direitos e garantias ficaram restringidos, ou revogados;

13/ Discriminação das mulheres na análise e na procura de respostas à pandemia e aos seus impactos

Ausência das mulheres e das suas perspectivas e necessidades, sobretudo das mais atingidas por todos estes problemas, nas análises dos problemas da nação e na formulação de políticas e tomada de decisóes tanto para o período de emergência quanto na fase de recuperação social e econômica subsequente de pós-emergência.

\section{Considerações finais}

O caráter financeiro e extrativista da economia neoliberal contemporânea está a levar ainda mais longe a desarticulação entre trabalho e a produção de vida: a vida deixa de ser uma condição existencial para se tornar um privilégio de alguns e pouquíssimas algumas. Isso fica especialmente claro nos processos acelerados e selvagens de urbanizaçáo que criam aglomeraçóes gigantescas de pessoas que vivem em condições de absoluta insalubridade e falta de segurança de todos os tipos. Esse tipo de urbanização é extremamente violenta contra as pessoas que se amontoam transformando-as em reserva de mão de obra 
totalmente precária, muitas vezes escrava, disponível para qualquer tipo de produçáo industrial intensiva, comércio, atividades ilícitas, e descartável quando não se mantêm funcional; é extraordinariamente violenta contra os territórios que invade e pretende domesticar; destrói e aniquila identidades e dinâmicas existentes transformando os espaços em meros "pedaços de cháo ocupado" ao serviço dos interesses de uma economia para a qual a vida, em todas as suas formas, é uma mera abstração, quando não um obstáculo ao seu único desígnio de acumulação de lucro.

As pandemias dos séculos XX e XXI são efeitos diretos destas dinâmicas criadoras de reservas de trabalho não pago nem reconhecido e de extensas periferias onde a possibilidade de viver com dignidade é muito difícil e onde as violências são uma das formas mais comuns para resolver as tensões e os conflitos. Nelas desinfectar e/ou lavar as mãos com a regularidade necessária ou manter o afastamento social para evitar contaminaçóes, na maioria das vezes, não é uma escolha quanto mais um direito. Nelas, e apesar de todas as dificuldades, são as mulheres que na sua maioria geram e reinventam, a todo o instante, as condiçóes concretas que possibilitam a vida a cada dia. Essas periferias, que em tempos de pandemia são redobradamente acusadas de espalhar as doenças e lixo, são lugares de inferno para a maioria das pessoas do mundo e, ao mesmo tempo, são os lugares de maior imaginação criativa e superação para encontrar respostas e alternativas às mais extremas condiçōes de vida e de morte. Estas periferias, tanto materiais quanto conceituais, existem em todos os lugares do mundo e são uma das realizaçóes mais brutais do sistema colonial que se perpetua, de muitas maneiras, nos nossos dias: invadir, usurpar, subjugar e ocupar em nome dos interesses dos velhos e novos conquistadores que querem instaurar uma ordem colonial que procura impor um pacto social invertido: viver sem produzir e enriquecer à custa da vida.

Em período de pandemia pelo novo Coronavírus a mais insurgente das reflexóes é afirmar que a economia não parou e a vida também não parou. Ao contrário, as economias que produzem a vida incessantemente, estão a funcionar na sua máxima capacidade para proteger, alimentar, abrigar, curar, cuidar, produzir alimentos, limpar, apoiar e amar. Contra-a-corrente da ideia de mais uma recessão econômica global, há que espalhar a notícia de que a economia baseada no crescimento sem limites e na concentração da riqueza está a falir diante dos nossos olhos e precisamos discernir, nestes tempos temerosos, onde estâo a chegar os sinais que nos podem salvar agora e no futuro. Esses sinais, essas alternativas estão em marcha, ainda que, muitas vezes, silenciadas, desprezadas e fragilizadas por todas as desconfianças lançadas sobre elas. Porém permanecem, acintosamente, presentes nos nossos dias de confinamento.

Como afirma Maristella Svampa (2020), se há um inimigo que nos ataca 
e atemoriza ele não é o novo Coronavírus em si mesmo, mas sim, o que causa essa e outras pandemias e desastres. A verdadeira e substantiva guerra é aquela que é travada pelo capitalismo contemporâneo contra a igualdade, a equidade, a democracia, a justiça social, sexual e cognitiva, a solidariedade, a dignidade, o respeito e a biodiversidade. Estamos perante um sistema econômico colonial, antissocial, antidemocrático, misógino, violento e ecocida protagonizado por uma pequena elite, composta, na sua esmagadora maioria, por homens, cujo ideal de masculinidade é o espelho perfeito do sistema que controlam (SHIVA, SHIVA, 2020). Para o contrariar precisamos, como humanidade, colocar no centro o cuidado com a vida em todas as suas manifestaçóes.

\section{Referências}

AFONSO, N. Dia da Consciência Negra: números expóem desigualdade racial no Brasil. Revista Piauí, Folha de São Paulo, 2019. Disponível em https://piaui.folha.uol. com.br/lupa/2019/11/20/consciencia-negra-numeros-brasil/ Acessado em: 20 Jan 21.

ANDRADE, J. Quem são os 33 novos bilionários brasileiros. Forbes, 18 Set 20, 2020. Disponível em https://forbes.com.br/listas/2020/09/acionistas-da-wegsomam-dez-dos-33-novos-bilionarios-brasileiros/ Acessado em: 26 Jan 21.

BLOOMBERG (2021). Bloomberg Billionaires Index. Bloomberg. Disponível em https://www.bloomberg.com/billionaires/ Acessado em: 25 Jan 21.

BRAH, A.; PHOENIX, A. Ain't I A Woman? Revisiting intersectionality. Journal of International Women's Studies, Vol 5 (3), 2004.

BRASIL. Taxa de feminicídios no Brasil é a quinta maior do mundo. AgênciaBRASIL, 27 Ago 2017, 2017. Disponível em https://agenciabrasil.ebc. com.br/direitos-humanos/noticia/2017-08/taxa-de-feminicidios-no-brasil-equinta-maior-do-mundo Acessado em: 23 Jan 21.

CANAL RURAL. Bill Gates: de rei da tecnologia a maior proprietário de terras agrícolas nos EUA. Bilionário do ramo de tecnologia, ele é dono de $97 \mathrm{mil}$ hectares, distribuídos em 18 dos 50 estados americanos. CanalRural, 15 Jan 21, 2021. Disponível em https://www.canalrural.com.br/noticias/agricultura/billgates-maior-proprietario-terras-eua/ Acessado em: 23 Jan 21.

CASTEL-BRANCO, C. N. 'Economia extractiva e desafios de industrialização em Moçambique', In Luís Brito, Carlos Nuno Castel-Branco; Sérgio Chichava; António Francisco (Orgs.). Economia extractiva e desafios de industrializaçáo em Moçambique. Maputo: IESE, p. 19-109, 2010. 
COUNTRY METERS (s/d). Population of the world and countries. Disponível em https://countrymeters.inf Acessado em: 25 Jan 21.

CUNHA, T. Never Trust Sindarela. Feminismos, Pós-colonialismos, Moçambique e Timor-Leste. Coimbra: Almedina, 2014.

CUNHA, T. Todo o trabalho é produtivo: economias de abundância e da sobriedade. In Xoán Hermida González (Coord.). [Re]Pensar a democracia. Corunha-Galícia: Foro obencomún, p. 101-134, 2017.

FEDERICI, S. Caliban and the witch: Women, the Body and Primitive Accumulation. Brooklin-NY: Autonomedia, 2004.

FEDERICI, S. Revolución en punto cero. Trabajo doméstico, reproducción y luchas feministas. Trad. Carlos Fernández Guervós y Paula Martín Ponz. 2a Ed. Madrid: Traficantes de Sueños, 2018.

FEDERICI, S. Mulheres e caça às bruxas: da Idade Média aos dias atuais. Trad. Heci Regina Candiani. São Paulo: Boitempo, 2019.

FUKS, R. Quem são as pessoas mais ricas do Brasil em 2020. ebiografia.com, atualizado em 13 Jan 21, 2021. Disponível em https://www.ebiografia.com/ pessoas_mais_ricas_do_brasil/ Acessado em: 23 Jan 21 .

GAGO, V. Financialization of Popular Life and the Extractive Operations of Capital: A Perspective from Argentina. Trad. Liz Mason-Deese. The South Atlantic Quarterly, 114(1), p. 11-28. Duke University Press, 2015.

GLAMURAMA. Bill Gates compra propriedade de 97 mil hectares e se torna o maior dono de terras dos EUA. Glamurama, 15 Jan 21, 2021. Disponível em https://glamurama.uol.com.br/bill-gates-compra-propriedade-de-97-milhectares-e-se-torna-o-maior-dono-de-terras-dos-eua/ Acessado em: 23 Jan 21.

GONZALES, L. Racismo e sexismo na cultura brasileira. Revista Ciências Sociais Hoje, Anpocs, p. 223-244, 1984.

MCCLINTOCK, A. Imperial Leather: Race, Gender, and Sexuality in the Colonial Contex. New York: Routledge, 1995.

MENDOZA, B. La epistemología del sur, la colonialidad del género y el feminismo latino-americano. In Aproximaciones críticas a las prácticas teóricopolíticas del feminismo latino-americano. Coord. Yuderkys Espinosa Miñoso. 1a ed. Buenos Aires: En la Frontera, p.19-36, 2010.

MIES, M. Patriarchy and Accumulation on a World Scale: Women in the International Division of Labour. First published in 1986. London: Zed Books, 2014. 
MILANEZ, F; VIDA, S. Pandemia, racismo e genocídio indígena e negro no Brasil: coronavírus e a política de extermínio. In Pensar la pandemia. Observatorio Social del Coronavirus. CLACSO, 2020. Disponível em https:// www.clacso.org/pandemia-racismo-e-genocidio-indigena-e-negro-no-brasilcoronavirus-e-a-politica-de-exterminio/ em 22 Jan 21.

MOÇAMBIQUE. Prevalência do HIV aumenta para 13,2 por cento em Moçambique. Portal do Governo de Moçambique, s/d. Disponível em https:// dev.portaldogoverno.gov.mz/por/Imprensa/Noticias/Prevalencia-do-HIVaumenta-para-13-2-por-cento-em-Mocambique Acessado em: 25 Jan 21.

MUNDI, I. Moçambique densidade médicos. IndexMundi, s/d. Disponível em https://www.indexmundi.com/pt/mocambique/densidade_de_medicos.html

OCHA-SERVICES. Gender implications of COVID-19 outbreaks in development and humanitarian settings. CARE, 2020. Disponível em https://reliefweb.int/report/world/gender-implications-covid-19-outbreaksdevelopment-and-humanitarian-settings Acessado em: 25 Jan 21.

OSÓRIO, C.; SILVA, T. C. e. Silenciando a discriminaçáo. Conflitos entre fontes de poder e os direitos humanos das mulheres em Pemba. Maputo: WLSA, 2018.

OXFAM-BRASIL. Mais pessoas morrerão de fome no mundo do que de covid-19 em 2020. OXFAM-Brasil, 2020a. Disponível https://www.oxfam.org. $\mathrm{br} /$ noticias/mais-pessoas-morrerao-de-fome-no-mundo-do-que-de-covid-19em-2020/ Acessado em: 05 Ago 2020.

OXFAM-BRASIL. Tempo de cuidar: o trabalho de cuidado náo remunerado e mal pago e a crise global da desigualdade. OXFAM-Brasil, 2020b. Disponível em https:/www.oxfam.org.br/justica-social-e-economica/forum-economico-dedavos/tempo-de-cuidar/ Acessado em: 24 Jan 21.

OYĚWÙMÍ, O. The Invention of Women: Making an African Sense of Western Gender Discourses. Minneapolis, MN: University of Minnesota Press, 1997.

PÉREZ OROZCO, A. Perspectivas feministas en torno a la economía: el caso de los cuidados. Madrid: Consejo Económico y Social - CES, 2006.

PÉREZ OROZCO, A. Subversión feminista de la economía. Aportes para un debate sobre el conflicto capital-vida. $3^{\mathrm{a}}$ ed. Madrid: Traficantes de Sueños, 2017.

SCHWARCZ, L. M. Sobre o autoritarismo brasileiro. 1aed. São Paulo: Companhia das Letras, 2020.

SEGURANÇA PÚBLICA. Anuário Brasileiro de Segurança Pública 2019. Fórum Brasileiro de Segurança Pública, 2019. Disponível em 
http://www.forumseguranca.org.br/wp-content/uploads/2019/10/Anuario2019-FINAL_21.10.19.pdf Acessado em: 22 Jan 21.

SHIVA, V. A virus, humanity, and the earth. Deccan Herald News, 05 Ap 20, 2020a. Disponível em https:/www.deccanherald.com/specials/sunday-spotlight/ criminal-law-reforms-arbitrary-panel-ad-hoc-process-inherent-biases-886717. html Acessado em: 28 Mai 20.

SHIVA, V. Vandana Shiva sobre el coronavirus: de los bosques a nuestras granjas, a nuestro microbioma intestinal. Lavaca, 2020b. Disponível em: https://www. lavaca.org/notas/vandana-shiva-sobre-el-coronavirus-de-los-bosques-a-nuestrasgranjas-a-nuestro-microbioma-intestinal/ Acessado em: 03 abril 2020.

SHIVA, V.; SHIVA, K. Oneness vs. the 1\%: Shattering Illusions, Seeding Freedom. London: Chelsea Green, 2020.

SVAMPA, M. Feminismos del Sur y ecofeminismo, Buenos Aires, Nueva Sociedad, n. 256, p. 127-131, 2015.

SVAMPA, M. Las fronteras del Neoextractivismo en América Latina. Conflictos socioambientales, giro ecoterritorial y nuevas dependencias. Guadalajara, México: Universidad de Guadalajara y CALAS, 2019.

SVAMPA, M. Reflexiones para un mundo post-coronavirus. Nueva Sociedad, Abril, 2020. Disponível em https://www.nuso.org/articulo/reflexiones-para-unmundo-post-coronavirus/ Acessado em: 30 Ago 20.

UN. COVID-19 could lead to millions of unintended pregnancies, new UNbacked data reveals. United Nations News, 28 Apr 20, 2020. Disponível em https://news.un.org/en/story/2020/04/1062742 Acessado em: 24 Jan 21.

UNICEF ( $\mathrm{s} / \mathrm{d})$. Casamento prematuro em Moçambique. Moçambique tem uma das taxas mais elevadas de casamento prematuro do mundo. Unicef, s/d Disponível em https://www.unicef.org/mozambique/casamento-prematuro-emmo\%C3\%A7ambique Acessado em: 15 Dez 20.

USP. Dados do IBGE mostram que $54 \%$ da população brasileira é negra. Eunice Prudente destaca que a mulher negra sofre uma tripla forma dediscriminação porque é mulher, negra e pobre. Jornal da USP, 31 Jul 20, 2020. Disponível em https://jornal.usp.br/radio-usp/dados-do-ibge-mostram-que-54-da-populacaobrasileira-e-negra/ Acessado em: em 24 Jan 21. 